\title{
Environmental diagnosis of landfills in Venezuela using EVIAVE methodology
}

\author{
A. Paolini ${ }^{1}$, A. Ramos $^{2}$ \& M. Zamorano ${ }^{2}$ \\ ${ }^{I}$ Decanato de Ingeniería Civil, Departamento de Hidráulica y Sanitaria, \\ Universidad Centrocidental Lisandro Alvarado, Barquisimeto, Venezuela \\ ${ }^{2}$ Department of Civil Engineering, University of Granada, Spain
}

\begin{abstract}
The lack of modern and realistic waste management policies in Venezuela has led to uncontrolled waste dumping at landfills. Such landfills generate serious problems because of their location, design, and exploitation. Given this adverse state of affairs, it seems surprising that so little effort has been made to carry out an environmental diagnosis of landfill sites. The few existing studies have merely made inventories of waste disposal sites, and have limited themselves to pointing out the obvious, namely, the negative impact of such installations on the environment without determining cause-effect relations and without developing tools for defining strategic actions to solve this problem. The study presented in this paper uses EVIAVE, a method of environmental diagnosis developed by researchers at the University of Granada, to diagnose landfills in Venezuela. It was necessary to modify EVIAVE in order to adapt the method to the legal system and social context in Venezuela. The data obtained, after applying methodology to 22 landfills in the country, include a series of environmental indexes (Environment Landfill Index, Environmental Risk Index, Environmental Value Index and Probability of Contamination Index) which allowed us to quantify the relation of landfill dynamics and its influence on various environmental elements. The results of the study confirm that EVIAVE can be successfully used as a planning tool for strategic actions that will reduce the environmental impact produced by indiscriminate waste disposal.
\end{abstract}

Keywords: landfill, environmental impact, municipal waste, Venezuela, EVIAVE methodology. 


\section{Introduction}

Waste disposal in South American and the Caribbean countries is acknowledged to be a grave problem, especially in urban areas. However, up until now, the possible solutions proposed have not been implemented in these countries, or in the majority of small or medium-sized towns. The situation has thus become extremely serious [1-3]. According to the Pan-American Health Organization [4], the urban population in large South American cities produces 56.4\% of the total amount of solid waste. However, $21 \%$ of this waste is generated in medium-sized urban areas and $23 \%$ in small urban areas, which lack the infrastructures and human resources to carry out an effective program of waste management.

Municipal waste management in Venezuela contributes to this adverse state of affairs since in many cities waste is indiscriminately dumped. In fact, inadequate waste disposal is endemic all over the country [5]. In 1999 the Venezuelan Ministry of Environment and Renewable Resources [MERNR] made an inventory of landfills in the country. At that time, the report identified 215 sites, which were described by the authors as deficient [6]. They had inadequate or non-existent compaction and sealing, no gas and leachate control, no monitoring of the installations, waste scavenging in infrahuman conditions, presence of animals at the landfill, and a total lack of compliance with Venezuelan laws regarding urban waste disposal.

Despite this alarming situation, no program of actions has been designed to deal with the serious environmental problem generated. The only measures taken so far are those that target specific emergencies on a one-off basis, but are not part of a coherent framework of strategic actions that would be conducive to a global solution. Not surprisingly, no methods have been developed as decisionmaking tools for cleaning up waste dumping sites.

This research study presents the quantitative and qualitative assessment of municipal waste disposal in Venezuela with a view to defining the real dimensions of the problem as well as waste management needs and priorities. To do this, we have used EVIAVE, a method of environmental diagnosis developed by researchers at the University of Granada, and applied in Spain [7] and Chile [8]. In each case the method was adapted to the legal and social framework of the country involved.

\section{Materials and methods}

\subsection{Description of EVIAVE methodology}

EVIAVE methodology for the environmental diagnosis of landfills is based on the use of a series of environmental indexes that quantify the impact of landfills on the surrounding environment [7,8]. This method can be applied to landfills with non-hazardous waste, as defined by EU Directive 31/99/EU, regarding the elimination of solid waste in landfills in the European Union or in countries with similar or less restrictive laws $[7,8]$. 
According to EVIAVE, the degree to which a landfill affects the environment is caused by its level of exploitation as well as the environmental characteristics of its location, represented by the following five elements: surface water, ground water, atmosphere, soil, as well as health and society. The hierarchical structure for obtaining the environmental indexes has four levels (Figure 1): (i) landfill variables and environmental descriptors; (ii) Probability of Contamination (Pbc); (iii) Environmental Risk Index (ERI); (iv) Environment Landfill Index (ELI). The first three indexes are defined for each landfill and environmental element. The fourth index is defined for each landfill. Table 1 shows the formulas used to calculate them.

Table 1: Calculation of environmental indexes with EVIAVE methodology.

\begin{tabular}{|c|c|c|}
\hline \multicolumn{2}{|l|}{ Index } & Equation \\
\hline \multicolumn{2}{|c|}{ Environment Landfill Index (ELI) } & $E L I=\sum_{i=1}^{i=5} E R I_{i}$ \\
\hline \multicolumn{2}{|c|}{ Environmental Risk Index (ERI) } & $E R I_{i}=P b c_{i} \times V a_{i}$ \\
\hline \multirow{4}{*}{$\begin{array}{l}\text { Environmental } \\
\text { Value }(\mathrm{eV})\end{array}$} & Surface Water & $e V=\frac{A_{1}+A_{2}+A_{3}}{3}$ \\
\hline & Ground Water & $e V=\frac{B_{1}+B_{2}}{2}$ \\
\hline & Atmosphere & $\mathrm{eV}=C_{1}$ \\
\hline & Soil & $e V=\frac{D_{1}+D_{2}+D_{3}}{3}$ \\
\hline \multicolumn{2}{|c|}{ Probability of Contamination $(\mathrm{Pbc})$} & $P b c_{i}=\frac{\sum_{j=1}^{j=n} I R C_{j}-\sum_{j=1}^{j=n} I R C_{j \min }}{\sum_{j=1}^{j=n} I R C_{j \max }-\sum_{j=1}^{j=n} I R C_{j \min }}$ \\
\hline \multicolumn{2}{|c|}{ Contamination Risk Index (CRI) } & $I R C_{j}=C_{j} \times P_{j}$ \\
\hline
\end{tabular}

\subsection{Landfill selection and classification}

We used EVIAVE to analyze a total of 22 landfills, located in the Venezuelan states of Lara, Yaracuy, Cojedes, Trujillo and Mérida. These sites were selected because of their proximity to the state of Lara, residence of the author in charge of collecting data. An added advantage was the existence of information about the characteristics of these sites.

The landfills were classified in four groups: (i) open-air landfills with no restrictions on waste disposal and no environmental control; (ii) partially controlled landfills, which had been originally planned as sanitary landfills, however, their chaotic operation makes them open-air landfills; (iii) controlled landfills, subject to some waste management though in need of stricter monitoring and regulation; (iv) sanitary landfills in which waste dumping and disposal is strictly monitored.

\subsection{Statistical analysis}

The results obtained were statistically analyzed with the software application SPSS ${ }^{\circledR}$ (Copyright SPSS. Inc., 1089-2005, Version 14.0.1 for Windows, license 


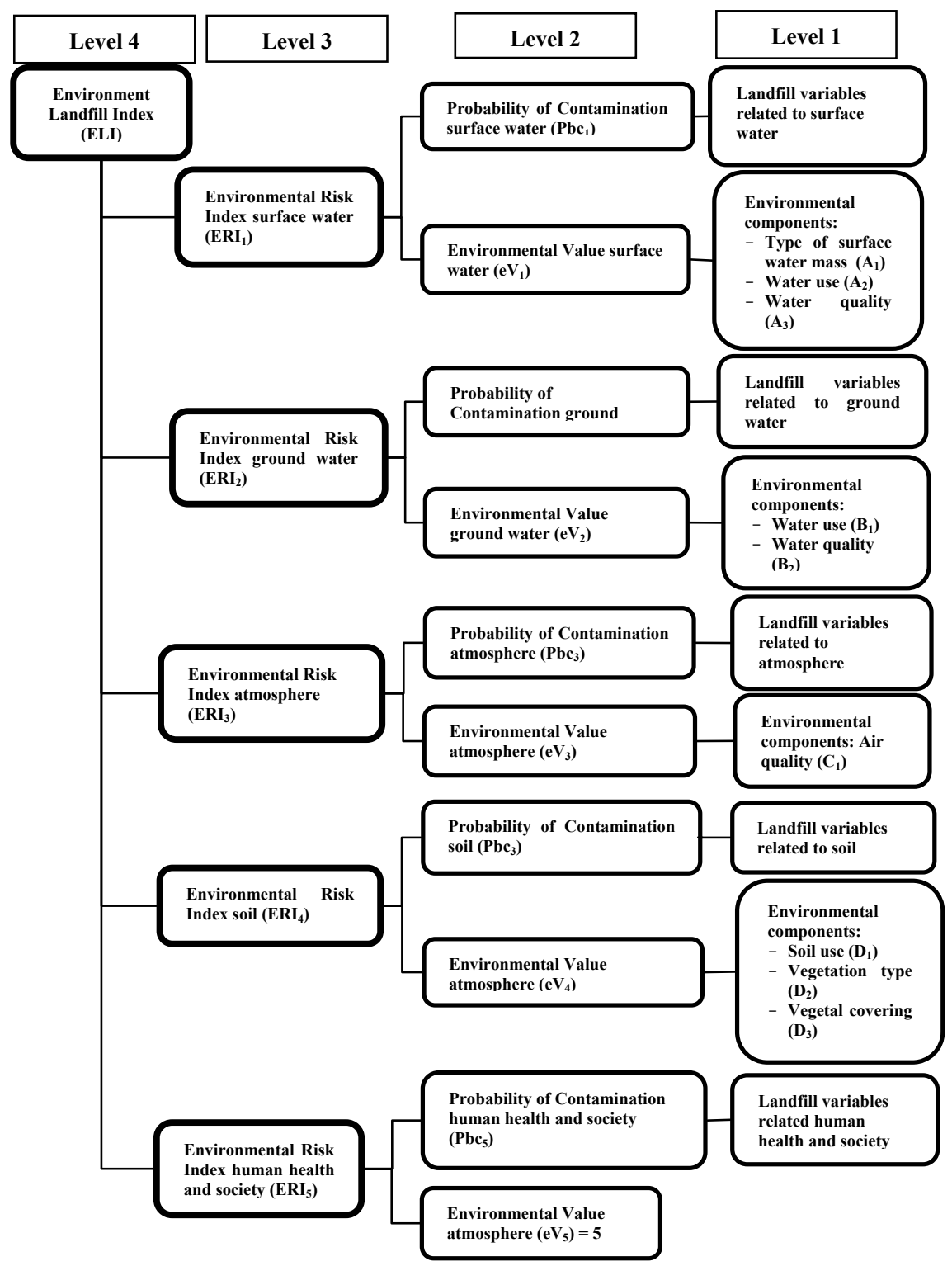

Figure 1: Methodology description.

purchased by the University of Granada). A single factor ANOVA (level of significance, 0.05) was used to analyze descriptive statistical data with the purpose of generating a variance analysis of one factor for various dependent variables (i.e. the environmental indexes generated by the methodology) in 
reference to one independent variable (i.e. environmental elements, landfill location, and landfills classification).

\section{Modification of the methodology}

The first phase in our research study was the analysis of all the variables and environmental descriptors, and their subsequent adaptation to the legal system and social characteristics of Venezuela. The resulting modifications did not affect the structure and objectives of the methodology, but only the conditions of certain variables and environmental descriptors.

\subsection{Modification of landfill variables}

Landfill variables were defined as those aspects or characteristics which, because of their sensitivity to biochemical and physical processes, directly or indirectly influence the degree to which environmental elements are affected. These variables permit the quantification of environmental risk because they are characteristic of the landfill site, and also measure the exploitation level of the landfill $[7,8]$. All of the variables have a theoretical justification, and their selection was based on numerous research studies on how landfills can affect the environment as well as the criteria set out in current regulations and guidelines in Europe and Spain $[7,8]$.

We revised all variables related to legal criteria and to specific social conditions in Venezuela, and variables that could not be applied because of the lack of technical information. Of the 26 variables in EVIAVE, 10 were modified.

\subsection{Modification of environmental descriptors}

The concept of Environmental Value is informative of the environmental importance of specific elements at the site, such as surface water, ground water, soil, atmosphere, and health $[7,8]$. Environmental Value identifies and quantifies the relation of each environmental element in the area to its environmental and/or socio-political characteristics and the emissions at the landfill. In this way, it was possible to identify a series of environmental components for each of the environmental elements at the site. These components define and quantify those environmental characteristics at the location, which would be most dramatically affected by the presence of a landfill. Their classification of these environmental descriptors was based on both European and Spanish environmental legislation.

Each environmental descriptor was analyzed and revised within the context of the legal framework in Venezuela to ascertain if it could be applied to the waste disposal situation in Venezuela. Also analyzed were the environmental descriptors which might be affected because of the specificity of Venezuelan ecosystems. After this revision, seven of the nine EVIAVE descriptors underwent some degree of modification. 


\section{Results and discussion}

\subsection{Application of the EVIAVE methodology}

Once the data was collected and analyzed at each waste dumping site, we applied EVIAVE (in its modified form) to the landfills in our study. Table 2 lists the indexes obtained for 5 of the 22 landfills studied.

\subsection{Environmental quantification of the overall condition of landfills}

The Environment Landfill Index gives and quantifies the overall condition of the landfills. In addition, it establishes an order of priority for actions to be taken, and thus facilitates strategic planning and decision-making. Landfills with a high ELI are those most in need of urgent sanitary measures. As can be observed (Table 3) the Pavia landfill has the lowest ELI (8.35), which signifies that its impact on the environment is low. In contrast, the Onia landfill (Table 3 ) has a high environmental impact, which is in consonance with its ELI (18).

Our results confirm those obtained in previous studies of the landfills sites. In this research, the Pavia Landfill was described as controlled [6,9] however, since this installation did not show optimal levels of exploitation and control, it could not be classified as a sanitary landfill. At the other end of the spectrum, was the Onia Landfill, defined in previous studies as an open-air landfill where there was absolutely no monitoring and control where negative factors were observed [5].

The single factor ANOVA of the ELI shows the absence of statistically significant differences of the ELI in relation to the states (sig. $=0.921$ ); this indicates that they have similar environmental problems. We also analyzed the ELI of the landfills in relation to their exploitation level; our results show that if the exploitation and design of the landfills improves, the index decreases.

\subsection{Quantification of the effect of waste dumping sites on environmental elements in the area}

The EVIAVE diagnostic method quantifies the degree to which the landfills affect each environmental element. This is shown in the Environmental Risk Index (ERI) calculated for each of them (Table 2).

The result of the single factor ANOVA carried out for the ERIs shows the existence of statistically significant differences for environmental elements (sig $=0.000$ ). In this sense we carried out a multiple comparison of the ERI (Tukey's HSD Post Hoc Test), which established two homogeneous subgroups: the first group was made up of the environmental elements with the least risk of being affected by the landfills (surface water, ground water, and soil); the second group comprised atmosphere, and health and society, which were the environmental elements most at risk. These results confirm the health problem generated by such installations and highlight the existence of a totally inadequate operational structure in terms of sanitary conditions for the majority of landfills in South America and the Caribbean $[2,9,10]$ where it is frequent the presence of people 
who recover waste at landfills and thus subsequently spread diseases and infection among their families and acquaintances $[10,11]$.

\subsection{Landfill site suitability}

To analyze the suitability of landfill sites, Probability of Contamination because of location and Environmental Value were analyzed (Table 2).

Generally speaking, in Venezuela, previous field studies are never carried out before an area is designated as a viable landfill site. This means that all too often landfills are placed in an area where the environmental elements are vulnerable to the emissions from the landfill $[12,13]$. The results obtained show that many of the landfill sites in our study have a high environmental value because the surface water and ground water in the area are very important for the local population, or also because the characteristics of the air quality are regarded as acceptable to protect health and the atmosphere (e.g. Onia and Jiménez). The Probability of Contamination due to site location (Tables 2 and 3) also shows the existence of landfills affecting protected areas (e.g. Los Palmares).

The analysis of these indexes classifies landfill sites in three groups: (i) adequate, applicable to five landfills (e.g. Pavia); (ii) inadequate, applicable to twelve dumping sites (e.g. Onia and Los Palmares); (iii) finally, there are a five landfill sites that need further study to decide whether these sites should be sealed (e.g. Curva del Viento).

\subsection{Suitability of exploitation}

The quantification of the effects of the landfill, caused by its management and exploitation are given by the Probability of Contamination Index related to exploitation (Pbco) (Table 2); they show for all environmental elements and landfills high or very high values. These results highlight the absence of the basic infrastructures necessary to minimize the negative effects of emissions generated by the landfills. Open-air landfills without any type of exploitation (e.g. Las Palmares, Onia, and Quebrada del Toro) have the highest indexes.

\section{Conclusions}

In order to apply EVIAVE to landfills in Venezuela, it was first necessary to adapt the diagnostic method with the legal system and the social reality in the country. The modifications made were not structural, but only affected the criteria established for the classification of certain landfill variables and environmental descriptors.

This modified version of EVIAVE was applied to 22 waste dumping sites. Environmental indexes obtained have quantified the extent to which the landfills affected the surrounding environment confirming that most of the landfills analyzed have deficient levels of exploitation and are located at unsuitable sites.

EVIAVE can be regarded as an effective planning tool, which facilitates the specification of action programs to improve the design and exploitation of landfills in Venezuela with a view to minimizing environmental risk. 
180 Waste Management and the Environment IV

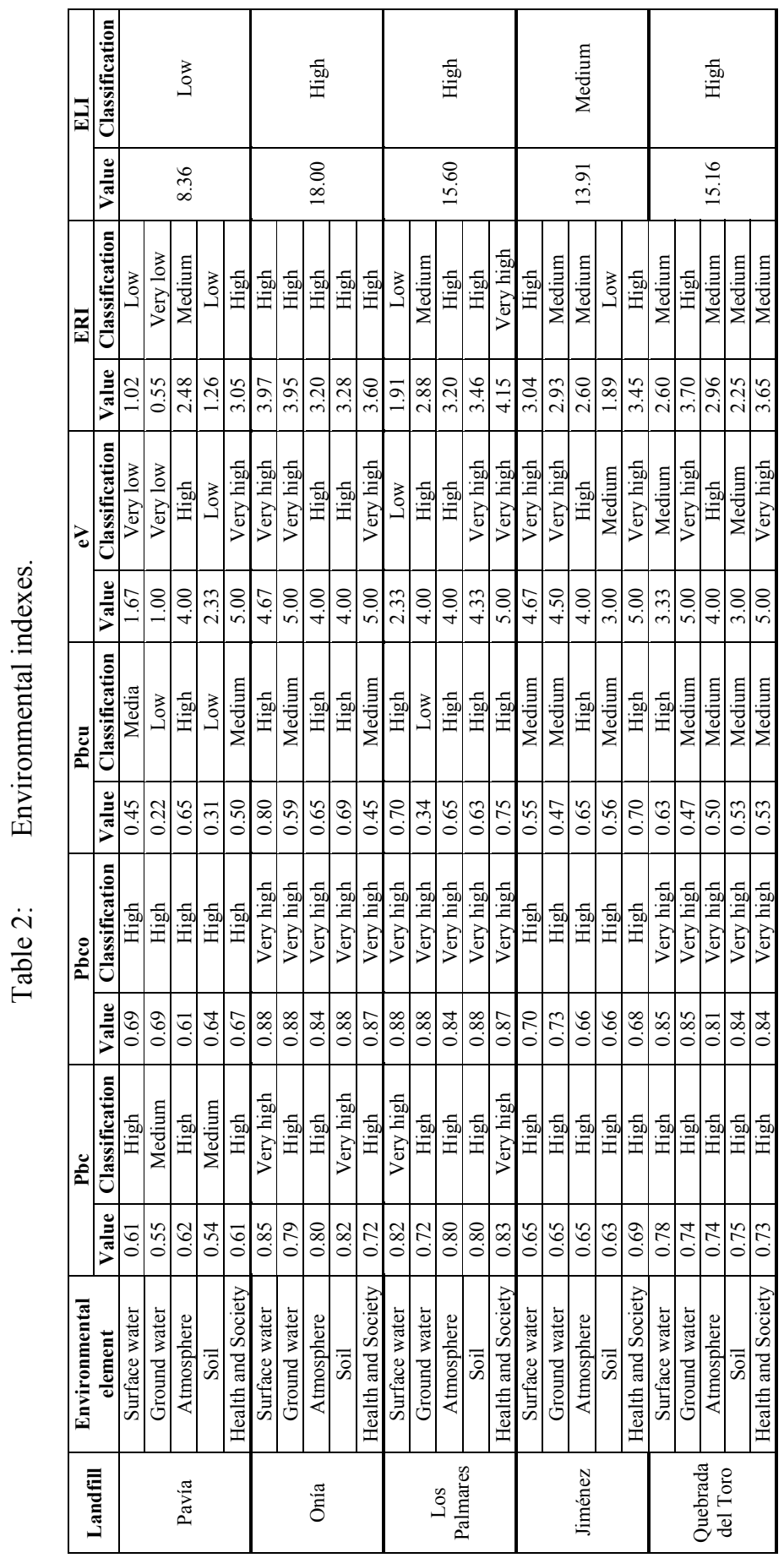


Table 3: $\quad$ Environment landfill index.

\begin{tabular}{|l|c|c|c|}
\hline \multirow{2}{*}{ Landfills } & \multirow{2}{*}{ Order of priority } & \multicolumn{2}{|c|}{ ELI } \\
\cline { 3 - 4 } & 1 & Value & Classification \\
\hline Onía & 2 & 18.00 & High \\
\hline Chaparalito & 3 & 15.99 & High \\
\hline La Pica & 4 & 15.61 & High \\
\hline Los Palmares & 5 & 15.60 & High \\
\hline Sucre & 6 & 15.29 & High \\
\hline Quebrada del Toro & 7 & 14.89 & Migh \\
\hline Jaime & 8 & 13.91 & Medium \\
\hline Jiménez & 9 & 13.45 & Medium \\
\hline Andrés Bello & 10 & 13.29 & Medium \\
\hline San Felipe & 11 & 12.84 & Medium \\
\hline Chirico & 12 & 12.14 & Medium \\
\hline Lomas de Bonilla & 13 & 12.10 & Medium \\
\hline Bocono & 14 & 11.98 & Medium \\
\hline Barinas & 15 & 11.94 & Medium \\
\hline Los Jebes & 16 & 11.80 & Medium \\
\hline Guanarito & 17 & 11.51 & Medium \\
\hline Curva del viento & 18 & 11.46 & Medium \\
\hline El Balcón & 19 & 10.99 & Medium \\
\hline La Jabonera & 20 & 10.99 & Medium \\
\hline La Paraguita & 21 & 10.12 & Medium \\
\hline Tapa La Lucha & 22 & 8.36 & Low \\
\hline Pavía & & \multicolumn{2}{|c}{} \\
\hline
\end{tabular}

\section{Acknowledgements}

This research has been partially supported by Spanish Ministry of Science and Technology (TIC 2002-04330-C02-01).

\section{References}

[1] Díaz, L.F., La situación del manejo de los residuos sólidos en América Latina y El Caribe. Revista Técnica Residuos, 40, pp. 78-80, 1998.

[2] Calvo, F., Szanto, M. \& Muñoz, J., Situación del manejo de residuos sólidos urbanos en América Latina y El Caribe. Revista Técnica Residuos, 43, pp. 70-76, 1998

[3] Diaz, L.F., Savage, G.M. \& Egerth, L.L., Alternatives for the treatment and disposal of healthcare waste in developing countries. Waste Management, 25(6), pp. 626-636, 2005

[4] OPS (Organización Panamericana de la Salud) Informe regional sobre la evaluación de los servicios de manejo de residuos sólidos municipales en la Región de América Latina y el Caribe. Área de Desarrollo Sostenible y Salud Ambiental. Washington, D.C. OPS, 2005.

[5] Rondón, M., Herrera, E., Delgado, J.M., Rojas, N., Vera, B., Monroy, E., Sánchez, C., Mora, W. \& Sánchez, N., Evaluación regional de los servicios de manejo de residuos sólidos municipales. Informe Analítico de 
Venezuela. Organización Panamericana de la Salud. Oficina Regional de la Organización Mundial de la Salud, 2003

[6] Agelvis, R., Naranjo, H., Rincones, M. \& Sánchez, R., Diagnóstico de la situación actual de algunos sitios de disposición final en Venezuela. Revista de la Facultad de Ingeniería de la UCV, 14 (1), pp. 17-32, 1999.

[7] Zamorano, M., Garrido E., Moreno B., Paolini, A. \& Ramos, A., Description of the methodology EVIAVE for environmental diagnosis of municipal waste landfills. Journal of Sustainable Development and Planning, 1(3), pp. 1-14, 2006.

[8] Calvo, F., Moreno, B., Zamorano, M. \& Ramos, A., Implementation of a new environmental impact assessment for municipal waste landfills as tool for planning and decision-making process. Renewable \& sustainable energy reviews, 11(1), pp. 98-115, 2007.

[9] MARNR (Ministerio del Ambiente y los Recursos Naturales Renovables) Inventario nacional de sitios de disposición final de desechos sólidos. Informe Técnico. Caracas, 1999.

[10] Sivertsen, B. Air pollution impacts from open air burning. Waste. International conference on waste management and the environment, 3, Malta 2006. Waste management and the environment, III. Ed. by V. Popov et al. Southampton, WIT press, 2006.

[11] Krajewski, J.A., Szarapinska-Kwaszewska, J., Dudkiewicz, B., Cyprowski, M., Tarkowski, S., Konczalik, J. \& Stroszejn- Mrowca, G., Assessment of exposure to bioaerosols in workplace ambient air during municipal waste collection and disposal. Medycyna Pracy, 52 (6), pp. 417-422, 2001.

[12] Zepeda, F. El manejo de residuos sólidos municipales en América Latina y el Caribe. Serie Ambiental No 15. Organización Panamericana de la Salud. División de Salud y Ambiente. Washington D.C, 1995

[13] INAPMAS (Instituto Nacional de protección al Medio Ambiente y la Salud). Tecnologías aplicadas para el manejo y disposición de los residuos sólidos urbanos. Ministerio de Salud del Perú. Lima, 2003 